\title{
ANALISIS TINGKAT KESEJAHTERAAN MASYARAKAT NELAYAN DI DESA LERO KECAMATAN SINDUE KABUPATEN DONGGALA
}

\author{
Mulviana $^{\text {a }}$ Alimudin Laapo ${ }^{b}$ \\ a Mahasiswa Program Studi Pendidikan Geografi Fakultas Keguruan dan Ilmu Pendidikan Universitas Tadulako, Jln. \\ Kantor Bahasa No. 2, Palu (94119), Indonesia \\ ${ }^{b}$ Jurusan Sosial Ekonomi Pertanian Fakultas Pertanian Universitas Tadulako, Perdos Untad Blok B3/14 Tondo, Palu \\ (94119), Indonesia
}

\begin{tabular}{ll}
\hline INFO ARTIKEL & ABSTRACT \\
\hline Status artikel: & $\begin{array}{l}\text { The objectives of this research are: (1) to find out the Welfare Level of the Fishermen } \\
\text { according to the World Bank (2) to find out the Welfare Level of the Lero Village }\end{array}$ \\
$\begin{array}{l}\text { Diterima: 19-01-2021 } \\
\text { Disetujui: 02-03-2021 }\end{array}$ & $\begin{array}{l}\text { Fishermen based on the Central Bureau of Statistics. Data were collected using } \\
\text { observation, questionnaires, interviews, and documentation. Data analysis used in } \\
\text { Tersedia online: 04-03-2021 }\end{array}$ \\
& $\begin{array}{l}\text { measuring fishermen's welfare using the income approach and BPS criteria. The results } \\
\text { of the research show that (1) Based on the net income of fishermen for a month is IDR. }\end{array}$ \\
839.413, which means less than World Bank standards, it can be categorized as poor or \\
not yet prosperous. (2) Based on the sum of the calculation of the recapitulation of \\
Fishermen, & $\begin{array}{l}\text { welfare indicators based on the Central Bureau of Statistics criteria, it shows that the } \\
\text { fishermen are at a moderate level of welfare, with a total score of } 15 .\end{array}$
\end{tabular}

Penulis korespondensi:

Mulviana,

Mahasiswa Program Studi Pendidikan Geografi Fakultas Keguruan dan Ilmu Pendidikan Universitas Tadulako, Jln. Kantor Bahasa No. 2, Palu (94119), Indonesia

Email: aminmulviana@gmail.com DOI: 10.34312/jgej.v2i1.9642

Copyright (C) 2021 The Authors

\begin{abstract}
ABSTRAK
Tujuan penelitan ini adalah : (1) Untuk mengetahui Tingkat Kesejahteraan Masyarakat Nelayan yang ada di Desa Lero, Kecamatan Sindue, Kabupaten Donggala menurut Bank Dunia (2) Untuk mengetahui Tingkat Kesejahteraan Masyarakat Nelayan yang ada di Desa Lero, Kecamatan Sindue, Kabupaten Donggala berdasarkan BPS. Metode pengumpulan data yang digunakan dalam penelitian ini yaitu observasi, angket, wawancara dan dokumentasi. Instrumen penelitian yang digunakan dalam penelitian ini yaitu angket, lembar observasi dan daftar wawancara. Analisis data yang digunakan dalam mengukur kesejahteraan nelayan menggunakan pendekatan pendapatan dan kriteria BPS. Hasil penelitian ini menunjukkan bahwa (1) Berdasarkan pendapatan bersih rumah tangga nelayan di Desa Lero selama sebulan yaitu sebesar Rp. 839.413 yang artinya kurang dari standar Bank Dunia, maka dapat diketahui nelayan di Desa tersebut dikategorikan sebagai penduduk miskin atau belum sejahtera (2) Berdasarkan penjumlahan dari perhitungan rekapitulasi indikator kesejahteraan berdasarkan kriteria BPS menunjukkan bahwa nelayan di Desa Lero berada pada tingkat kesejahteraan sedang, dengan jumlah skor adalah 15.
\end{abstract}

\section{Pendahuluan}

Masyarakat nelayan adalah masyarakat yang umumnya mendiami kawasan pesisir dengan kondisi sosial ekonomi dan berpenghasilan rendah sehingga identik dengan kemiskinan (Kobi \& Hendra, 2020). Kondisi ini bersumber dari lemahnya potensi manusia masyarakat nelayan dan kurangnya daya dukung lingkungan dalam memanfaatkan potensi alam dan sumber daya yang tersedia (Widjajanti et al., 2019). Menurut Sudarmo et al. (2015) beberapa permasalahan kompleks yang dihadapi mata pencaharian nelayan skala kecil diantaranya adalah permasalahan pemanfaatan sumberdaya pesisir, penurunan sumberdaya ikan, perubahan kontur kawasan pesisir, permasalahan krisis BBM, urbanisasi yang kesemuanya memberikan tekanan pada kawasan pesisir. Kawasan pesisir juga sangat rentan dengan bencana alam seperti tsunami, terjangan topan 
maupun badai (Erlania \& Radiarta, 2014), serta abrasi pantai akibat hilangnya ekosistem pesisir sebagai pelindung pantai.

Salah satu desa di Kecamatan Sindue, Kabupaten Donggala yang terletak di kawasan pesisir pantai dan memiliki potensi untuk pengembangan perikanan adalah Desa Lero. Desa ini terdiri dari 5 dusun yang mayoritas penduduknya bermata pencaharian sebagai petani sebanyak 225 jiwa, Nelayan 125 jiwa, PNS sebanyak 67 jiwa, buruh sebanyak 31 jiwa, swasta sebanyak 21 jiwa dan pedagang sebanyak 10 jiwa (Anonim, 2020).

Sumber daya perikanan yang cukup melimpah dapat dimanfaatkan masyarakat Desa Lero untuk meningkatkan kesejahteraan terutama yang bekerja sebagai nelayan. Memiliki potensi perikanan Laut yang cukup besar tidak menjamin kesejahteraan masyarakat di Desa Lero. Tetapi, potensi tersebut tidak akan berarti jika tidak bisa dikelola secara tepat seperti menggunakan keterlibatan teknologi dalam mengeksplorasi potensi sumber daya tersebut. Selain itu, pemerintah lebih fokus pada pembangunan yang berorientasi kearah sektor daratan.

Berdasarkan data dari Desa Lero bahwa masih ada 243 jiwa masyarakat yang masuk dalam kategori masyarakat miskin/belum sejahtera. Angka tersebut cukup besar karena 11\% dari jumlah seluruh masyarakat di Desa Lero, termasuk masyarakat yang bermata pencarian sebagai nelayan. Kehidupan nelayan di Desa Lero sangat bergantung pada hasil laut. Namun, beberapa kendala yang ditemui oleh nelayan ini sehingga hasil tangkapan yang didapat cenderung lebih sedikit. Kendala yang dimaksud berasal dari faktor alam seperti hujan dan angin kencang.

Berdasarkan informasi dari BMKG Stasiun Meteorologi Kelas II Mutiara SIS Aljufri menyatakan bahwa pada bulan April-Oktober biasanya berpotensi terjadi hujan dengan intesitas sedang hingga lebat dan angin kencang yang disertai petir atau kilat di daerah Donggala dan sekitarnya (Fitri, 2020). Kondisi ini terjadi karena menghangatnya suhu perairan sekitaran pulau Sulawesi ditambah dengan angin timuran yang berhembus. Akibat hujan dan angin kencang yang tidak menentu tersebut menyebabkan nelayan di Desa Lero tidak dapat bekerja secara optimal, sehingga akan berdampak pada pendapatan yang diterima oleh nelayan.

Selain karena faktor alam, peralatan tangkap yang masih sederhana/tradisional turut serta berpengaruh terhadap usaha penangkapan ikan nelayan. Hal ini disebabkan hasil tangkapannya cenderung lebih sedikit dibandingkan dengan nelayan yang sudah menggunakan teknologi peralatan tangkap yang modern. Nelayan di Desa Lero masih menggunakan alat tangkap yang masih tradisional seperti Sero dan Pancing Ulur.

Nelayan tradisional pada umumnya hidup dibawah garis kemiskinan. Hal ini disebabkan oleh ciri yang melekat pada mereka yaitu kondisi usaha yang subsistem, modal kecil, teknologi sederhana dan bersifat one day fishing (Firdaus \& Witomo, 2014). Peralatan tangkap yang masih tradisional dapat mempengaruhi banyak sedikitnya jumlah hasil tangkapan nelayan. Hasil tangkapan mereka dapatkan tidak menentu sehingga berakibat pada pendapatan nelayan yang rendah. Tidak menentunya pendapatan nelayan di Desa Lero dari kegiatan penangkapan berimbas pada kesejahteraan keluarga mereka. Hasil penangkapan adalah faktor utama jumlah pendapatan yang akan diperoleh nelayan, semakin banyak hasil tangkapan yang didapat maka semakin banyak pendapatan yang akan didapat oleh nelayan.

Besaran pendapatan yang diterima nelayan menunjukkan tingkat kesejahteraan rumah tangga masyarakat nelayan. Berdasarkan Bank Dunia pendapatan diatas dari US\$2/kapita/hari atau jika dirupiahkan sebesar Rp. 30.000,00 dikelompokkan sebagai penduduk tidak miskin, sebaliknya jika pendapatan diatas US\$ 2/kapita/hari dikelompokkan sebagai masyarakat miskin (Muflikhati et al., 2010; Nurwati, 2008). Selain dilihat dari besaran pendapatan, indikator kesejahteraan masyarakat dapat diukur berdasarkan kriteria BPS. Kriteria kesejahteraan menurut BPS diantaranya adalah pengeluaran/Konsumsi Rumah Tangga, Pendidikan, Kesehatan, Fasilitas Rumah Tinggal, Kualitas Rumah Tinggal, Status Kepemilikan dan Teknologi Informasi dan Komunikasi yang digunakan.

Berdasarkan latar belakang yang telah diuraikan sebelumnya, maka peneliti tertarik untuk mengetahui lebih lanjut mengenai kesejahteraan nelayan yang ada di Desa Lero sehingga penulis akan melakukan penelitian yang berjudul "Analisis Tingkat Kesejahteraan Nelayan di Desa Lero, Kecamatan Sindue, Kabupaten Donggala".

Adapun tujuan penelitian ini adalah (1) Untuk mengetahui Tingkat Kesejahteraan Masyarakat Nelayan yang ada di Desa Lero, Kecamatan Sindue, Kabupaten Donggala menurut Bank Dunia. (2) Untuk mengetahui Tingkat Kesejahteraan Masyarakat Nelayan yang ada di Desa Lero, Kecamatan Sindue, Kabupaten Donggala berdasarkan BPS. 


\section{Metode}

\subsection{Lokasi Penelitian}

Penelitian ini dilaksanakan di Desa Lero, Kecamatan Sindue, Kabupaten Donggala, Provinsi Sulawesi Tengah. Penentuan lokasi dalam penelitian ini dilakukan dengan pertimbangan bahwa di lokasi tersebut sebagian besar masyarakat bermata pencarian sebagai nelayan sebesar $26 \%$.

\subsection{Jenis Penelitian}

Jenis penelitian ini adalah penelitian deskriptif kuantitatif. Teknik analisis deskriptif kuantitatif merupakan analisis data dengan cara mendiskripsikan atau menggambarkan data yang telah terkumpul sebagaimana adanya tanpa bermaksud membuat kesimpulan yang berlaku untuk umum (Sugiyono, 2015). Deskripsi dilakukan untuk menganalisis pendapatan dan tingkat kesejahteraan nelayan di Desa Lero berdasarkan indikator-indikator yang telah ditetapkan Pendekatan yang digunakan dalam penelitian ini adalah pendekatan ekologi yang mengkaji kegiatan nelayan dalam memanfaatkan sumber daya alam (perikanan).

\subsection{Populasi dan Sampel}

Metode pengambilan sampel yang digunakan dalam penelitian ini adalah sampling purposive yaitu teknik penentuan sampel dengan pertimbangan tertentu (Sugiyono, 2018). Sampel dalam penelitian ini 25\% dari jumlah populasi nelayan yaitu 125 jiwa.

\subsection{Jenis dan Sumber Data}

Jenis data dan sumber yang digunakan dalam penelitian ini adalah data primer dan data sekunder. Data primer adalah data penelitian yang diperoleh secara langsung dari sumber data yang dikumpulkan secara khusus dan berhubungan langsung dengan hasil yang diteliti. Data primer yang digunakan dalam penelitian ini adalah hasil pengisian kuesioner, lembar observasi dan daftar wawancara oleh responden. Jenis data yang dikumpulkan adalah identitas responden, keadaan usaha penangkapan ikan, biaya investasi, biaya variabel, pengeluaran rumah tangga nelayan, pendidikan, kesehatan, kualitas tempat tinggal, fasilitas tempat tinggal, status kepemilikan rumah tinggal, dan kemudahan mengakses TIK. Data ini didapat dari sampel yang telah ditentukan sebelumnya. Sedangkan Data sekunder yaitu data yang diperoleh dari instansi terkait seperti BPS, Kantor Kepala Desa Lero, Kementerian Kelautan dan Perikanan dan Dinas Perikanan Kabupaten Donggala.

\subsection{Metode Pengumpulan Data}

Metode pengumpulan data yang digunakan dalam penelitian ini yaitu :

1. Metode observasi merupakan pengumpulan data yang dilakukan dengan cara mengadakan pengamatan dan pencatatan secara sistematis secara langsung pada tempat yang diamati. Metode ini digunakan untuk mengamati pola kehidupan masyarakat nelayan di Desa Lero secara langsung.

2. Angket adalah alat yang digunakan untuk mengumpulkan data berupa serangkaian pertanyaan yang diajukan kepada responden dengan alternatif pilihan jawaban untuk mendapatkan jawaban dari responden (Sabari, 2010). Angket yang digunakan dalam penelitian ini adalah angket tertutup karena alternatif jawabannya sudah tersedia. Data yang dikumpulkan dari angket digunakan untuk menganalisis tingkat kesejahteraan Masyarakat nelayan di Desa Lero berdasarkan kriteria BPS.

3. Wawancara adalah kegiatan pengumpulan data yang dilakukan dengan menanyakan langsung pada sumber informasi (Sabari, 2010)). Wawancara ini dilakukan jika data-data yang diperoleh dalam penelitian ini dirasa kurang lengkap, sehingga membutuhkan informasi tambahan yang dilakukan dengan cara bertanya langsung kepada responden terkait data dan informasi yang dibutuhkan oleh peneliti. Data wawancara yang dikumpulkan digunakan untuk menganalisis tingkat kesejahteraan masyarakat nelayan di Desa Lero menurut kriteria Bank Dunia.

4. Dokumentasi yaitu mencari data mengenai hal-hal atau variable yang berupa catatan, transkrip, buku, surat kabar, majalah, prasasti, notulen rapat, lengger, dan sebagainya (Arikunto, 2013) Pada teknik ini peneliti mengumpulkan dokumen berupa data dan informasi mengenai kesejahteraan berdasarkan indikator BPS serta artikel terkait kesejahteraan dan masyarakat nelayan.

\subsection{Analisis Data}


Analisis data yang digunakan dalam penelitian ini adalah menggunakan pendekatan pendapatan dan indikator berdasarkan BPS.

1. Analisis Pendapatan

Analisis tingkat kesejahteraan dilakukan dengan menggunakan pendekatan pendapatan perkapita/hari Menurut Bank Dunia yaitu US\$ 2/kapita/hari, tetapi pada penelitian ini pendapatan yang dihitung yaitu pendapatan nelayan selama sebulan sehingga standar yang digunakan sebesar US\$ 60/kapita/bulan atau jika dirupiahkan sebesar Rp. 900.000,00/bulan.

Menghitung jumlah pendapatan nelayan yang dimaksud adalah pendapatan bersih yang diperoleh menggunakan rumus sebagai berikut (Manggabarani, 2016) :

$$
\boldsymbol{\pi}=\boldsymbol{T R}-\boldsymbol{T C}
$$

Dimana :

$\pi=$ Pendapatan nelayan

$\mathrm{TR}=$ Penerimaan

TC = Biaya (Konsumsi, Rokok, Bahan Bakar dan Pelumas Armada, Umpan dll).

2. Kesejahteraan Menurut Indikator Badan Pusat Statistik (BPS)

Indikator yang digunakan untuk mengetahui tingkat kesejahteraan nelayan di Desa Lero adalah tingkat kesejahteraan menurut Badan Pusat Statistik (BPS) yaitu pengeluaran/konsumsi rumah tangga, pendidikan, Kesehatan, kualitas tempat tinggal, fasilitas tempat tinggal, status kepemilikan rumah tinggal serta ketersediaan infrastruktur dan kemudahan akses terhadap TIK. Berdasarkan hasil skoring dari indikator kesejahteraan tersebut, kemudian ditabulasi untuk mengetahui jumlah skor yang diperoleh. Menurut (BPS, 2019), kriteria masing-masing klasifikasi dapat dilihat pada tabel berikut.

Tabel 1. Kriteria skoring Indikator Kesejahteraan

\begin{tabular}{|c|c|c|c|}
\hline No. & Indikator Kesejahteraan & Kriteria & Skor \\
\hline \multirow[t]{3}{*}{1.} & \multirow[t]{3}{*}{$\begin{array}{l}\text { Pengeluaran/Konsumsi Rumah } \\
\text { Tangga }\end{array}$} & $\begin{array}{l}\text { Proporsi Pengeluaran Pangan dan Non } \\
\text { Pangan Seimbang }\end{array}$ & 3 \\
\hline & & $\begin{array}{l}\text { Proporsi Pengeluaran Pangan < Proporsi } \\
\text { Pengeluaran Non Pangan }\end{array}$ & 2 \\
\hline & & $\begin{array}{l}\text { Proporsi Pengeluaran Pangan }>\text { Proporsi } \\
\text { Pengeluaran Non Pangan }\end{array}$ & 1 \\
\hline \multirow[t]{3}{*}{2.} & \multirow[t]{3}{*}{ Pendidikan } & Tinggi $(>60 \%)$ & 3 \\
\hline & & Sedang $(30 \%-60 \%)$ & 2 \\
\hline & & Rendah $(<30 \%)$ & 1 \\
\hline \multirow[t]{3}{*}{3.} & \multirow[t]{3}{*}{ Kesehatan } & Bagus (13-15) & 3 \\
\hline & & Cukup (9-12) & 2 \\
\hline & & Kurang (5-8) & 1 \\
\hline \multirow[t]{3}{*}{4.} & \multirow[t]{3}{*}{ Kualitas Tempat Tinggal } & Permanen (14-17) & 3 \\
\hline & & Semi Permanen (9-13) & 2 \\
\hline & & Non Permanen (4-8) & 1 \\
\hline \multirow[t]{3}{*}{5.} & \multirow[t]{3}{*}{ Fasilitas Tempat Tinggal } & Lengkap (17-22) & 3 \\
\hline & & Cukup Lengkap (12-16) & 2 \\
\hline & & Kurang Lengkap (7-11) & 1 \\
\hline \multirow[t]{3}{*}{6.} & \multirow{3}{*}{$\begin{array}{l}\text { Status Kepemilikan Rumah } \\
\text { Tinggal }\end{array}$} & Milik Sendiri & 3 \\
\hline & & Kontrak/Sewa & 2 \\
\hline & & Milik Orang tua/Saudara & 1 \\
\hline \multirow[t]{3}{*}{7.} & \multirow[t]{3}{*}{ Kemudahan Mengakses TIK } & Bagus (12-14) & 3 \\
\hline & & Cukup (8-11) & 2 \\
\hline & & Kurang (4-7) & 1 \\
\hline
\end{tabular}

Sumber : (Sugiharto, 2007) (diolah) 
Berdasarkan Sugiyono (2008) cara penentuan rentang, kelas dan interval dalam proses scoring adalah sebagai berikut :

a) Penentuan rentang

$$
\begin{aligned}
& \mathrm{R}=(\text { Data terbesar }- \text { Data terkecil })+1 \\
& \mathrm{R}=(7 \times 3)-(7 \times 1)+1 \\
& \mathrm{R}=15
\end{aligned}
$$

b) Penentuan Panjang Kelas

$$
\begin{aligned}
& \text { Panjang kelas }=\frac{\text { Rentang }}{\text { Jumlah Kelas }} \\
& \text { Panjang kelas }=\frac{15}{3} \\
& \text { Panjang kelas }=4
\end{aligned}
$$

Berdasarkan penskoran setiap indikator maka dapat diturunkan berdasarkan tingkat kesejahteraan menurut BPS yaitu :
a. Tingkat Kesejahteraan Tinggi $=17-21$
b. Tingkat Kesejahteraan Sedang $=12-16$
c. Tingkat Kesejahteraan Rendah $=7-11$

\section{Hasil dan Pembahasan}

\subsection{Gambaran Umum Lokasi Penelitian}

Penelitian ini dilakukan di Desa Lero yang terletak di Kecamatan Sindue, Kabupaten Donggala, provinsi Sulawesi Tengah. Desa Lero terletak sebelah utara dari Kota Palu dan berjarak $\pm 45,1 \mathrm{~km}$. Desa ini memiliki luas wilayah $11,67 \mathrm{~km}^{2}$. Desa Lero terdiri dari 5 dusun yaitu Dusun I Pompaya, Dusun II Mpanau, Dusun III Kamboja, Dusun IV Pajeko dan Dusun V Bonda (Anonim, 2020).

Secara geografis gambar 1, Desa Lero berbatasan dengan dengan wilayah-wilayah sebagai berikut:

1. Sebelah Selatan Berbatasan Dengan Desa Lero Tatari

2. Sebelah Utara berbatasan dengan Desa Toaya Vunta

3. Sebelah Barat berbatasan dengan Selat Makassar

4. Sebelah Timur berbatasan dengan Desa Kumbasa

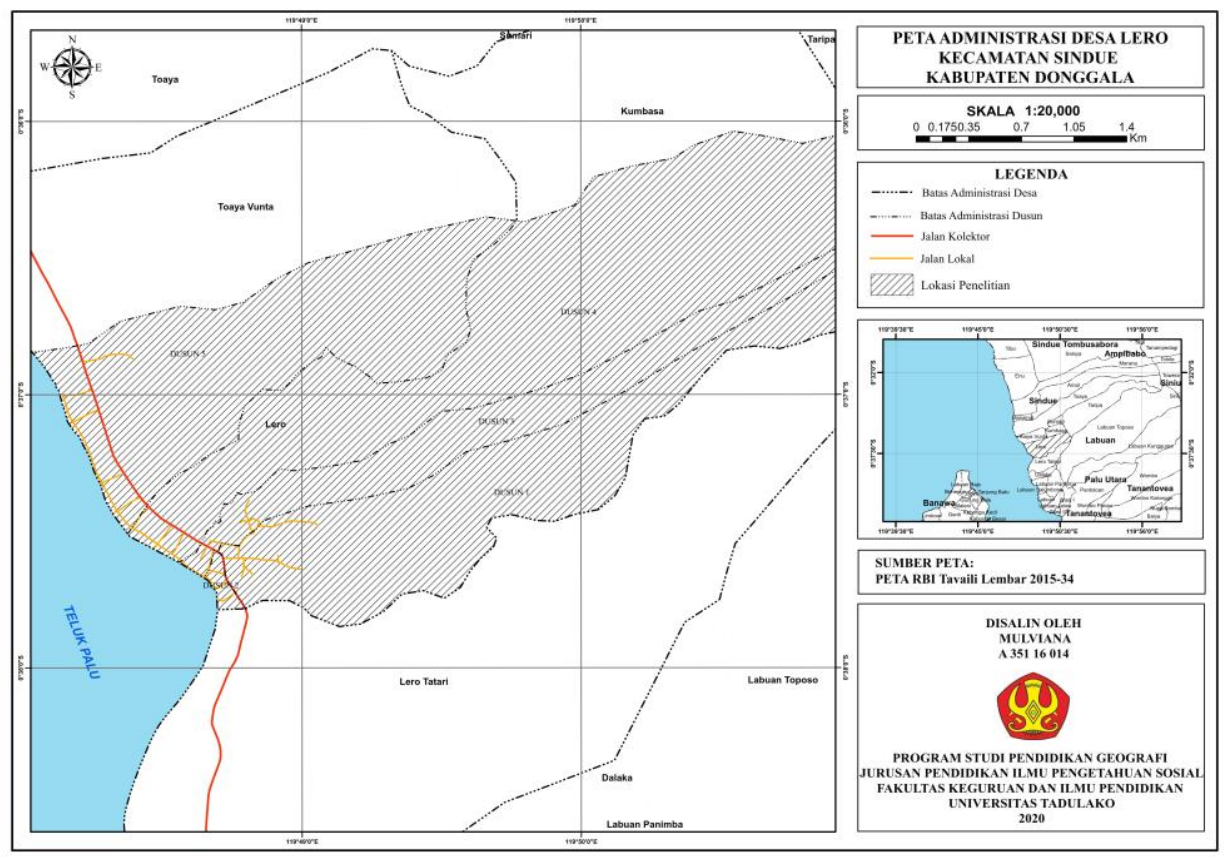




\section{Gambar 1. Peta Lokasi Penelitian}

\subsection{Karakteristik Responden Menurut Umur}

Badan Pusat Statistik (BPS) mengelompokkan umur di Indonesia dibagi menjadi tiga kategori yaitu belum produktif (0-14 tahun), produktif (15-64 tahun), dan tidak produktif ( $>65$ tahun). Berdasarkan hasil penelitian bahwa nelayan di Desa Lero $100 \%$ tergolong dalam umur produktif, sehingga nelayan di Desa tersebut dapat bekerja secara optimal.

\subsection{Karakteristik Responden Menurut Jumlah Tanggungan}

Berdasarkan penelitian, jumlah tanggungan nelayan di Desa Lero yang tertinggi adalah jumlah tanggungan $1-3$ orang dan jumlah tanggungan terendah adalah $7-9$ orang.

\subsection{Karakteristik Responden Menurut Pengalaman Melaut}

Berdasarkan hasil penelitian pengalaman melaut nelayan di Desa Lero berbeda-beda, pengalaman melaut terbesar berada pada interval 20-35 tahun dengan jumlah responden 15 orang atau sebesar $47 \%$. Sedangkan pengalaman laut terkecil adalah sebesar $15 \%$ atau berjumlah 5 orang berada pada interval $36-51$ tahun.

\subsection{Tingkat Kesejahteraan Berdasarkan Pendapatan}

Ukuran yang digunakan untuk menetapkan besarnya pendapatan yang diperoleh dari usaha penangkapan ikan yang menggunakan alat tangkap sero dan pancing ulur adalah selisih antara penerimaan dengan jumlah total biaya yang terdiri atas biaya variabel dan biaya tetap.

a. Penerimaan Nelayan

Penerimaan dalam usaha penangkapan adalah perkalian antara hasil produksi ikan dengan harga jual.

Berdasarkan hasil penelitian di Desa Lero, total rata-rata penerimaan nelayan adalah sebesar Rp. 483.900/bulan.

b. Biaya

Biaya terdiri dari 2 jenis yaitu biaya tetap dan biaya variabel. Biaya tetap tabel 2 adalah biaya yang relatif tetap jumlahnya dan terus dikeluarkan walaupun produksi atau hasil tangkapan yang diperoleh banyak atau sedikit. Biaya tetap yang diperhitungkan dalam penelitian ini meliputi biaya pemeliharaan dan biaya penyusutan alat seperti perahu, mesin dan genset. Biaya pemeliharaan adalah biaya yang dikeluarkan nelayan untuk pemeliharaan alat tangkap, perahu, oli untuk mesin.

Tabel 2. Rata-rata Biaya Tetap Nelayan per Bulan

\begin{tabular}{ccccccc}
\hline \multicolumn{7}{c}{ Biaya Tetap (Rp) } \\
\hline & Penyusutan & \multicolumn{5}{c}{ Pemeliharaan } \\
\hline Perahu & Mesin & Genset & Oli & Perahu & $\begin{array}{c}\text { Alat } \\
\text { Tangkap }\end{array}$ \\
\hline 91.978 & 85.476 & 45.112 & 105.750 & 19.584 & 46.193 & 394.093 \\
\hline \multicolumn{7}{c}{ Sumber : Pengolahan Data Primer, 2020. }
\end{tabular}

Sedangkan Biaya variabel tabel 3 adalah biaya yang dikeluarkan oleh nelayan pada usaha penangkapan yang habis dipakai dalam satu kali operasi penangkapan. Biaya variabel tersebut meliputi biaya bensin, es, umpan, perbekalan dan kue/snack.

Tabel 3. Rata-rata Biaya Variabel Nelayan per Bulan

\begin{tabular}{cccccc}
\hline \multicolumn{5}{c}{ Biaya Variabel (Rp) } & Jumlah \\
\hline Bensin & Es & Perbekalan & Umpan & Kue/Snack & \\
\hline 1.425 .333 & 443.522 & 731.538 & 450.000 & 300.000 & 3.350 .394 \\
\hline
\end{tabular}

Sumber : Pengolahan Data Primer, 2020

Menghitung total biaya yang dikeluarkan nelayan adalah dengan menjumlahkan biaya tetap (TFC) dengan biaya variabel (TVC). Jadi total biaya yang dikeluarkan nelayan yaitu Rp. 3.744.487. Setelah 
menghitung total penerimaan dan total biaya, maka dapat diketahui pendapatan bersih nelayan di Desa Lero adalah sebesar Rp. 839.413.

Penduduk yang tingkat pendapatannya dibawah US\$2/kapita/hari atau US\$ 30/kapita/bulan jika dirupiahkan sebesar Rp. 900.000/bulan, menurut standar Bank Dunia dikategorikan penduduk miskin absolut. Seseorang dikatakan miskin secara absolut apabila pendapatannya lebih rendah dari garis kemiskinan absolut atau dengan istilah lain jumlah pendapatannya tidak cukup untuk memenuhi kebutuhan hidup minimum (Nurwati, 2008).

Berdasarkan pendapatan bersih rumah tangga nelayan di Desa Lero selama sebulan yaitu Rp. 839.413 yang artinya kurang dari standar Bank Dunia, maka dapat diketahui nelayan di Desa tersebut dikategorikan sebagai penduduk miskin atau belum sejahtera. Nilai pendapatan nelayan di Desa Lero masih lebih rendah dibanding pendapatan nelayan di Kota Tegal (Sudarmo et al., 2015).

\subsection{Tingkat Kesejahteraan Berdasarkan Kriteria BPS}

a. Tingkat Kesejahteraan Berdasarkan Pengeluaran/Konsumsi Rumah Tangga

Pengeluaran rumah tangga terbagi menjadi dua yaitu pengeluaran pangan dan pengeluaran non pangan. Pengeluaran/konsumsi rumah tangga nelayan di Desa Lero terdiri dari beras, air minum, sayurmayur, ikan, buah-buahan, telur, susu, gula, teh, kopi, minyak goreng, mie, bumbu dapur, gorengan dan kue.

Berdasarkan hasil penelitian tabel 4 di Desa Lero rata-rata pengeluaran pangan tertinggi yaitu pengeluaran beras sebesar Rp. 493.031/bulan, sedangkan pengeluaran terendah yaitu teh sebesar Rp. 12.045/bulan. Sehingga, rata-rata total pengeluaran pangan nelayan di Desa Lero adalah Rp. $1.750 .397 /$ bulan.

Pengeluaran non pangan rumah tangga nelayan di Desa Lero terdiri atas pengeluaran untuk biaya listrik, biaya sandang (pakaian), biaya pendidikan anak, biaya transportasi, biaya telepon/pulsa, biaya kesehatan, biaya perlengkapan mandi, dan biaya LPG. Proporsi pengeluaran konsumsi pangan terhadap pengeluaran total rumah tangga adalah persentase pengeluaran pangan dibanding pengeluaran total.

Tabel 4. Proporsi Pengeluaran Non Pangan Rumah Nelayan terhadap Pengeluaran Total Rumah Tangga

\begin{tabular}{lllc}
\hline No. & \multicolumn{1}{c}{ Pengeluaran } & Rp/Bulan & Presentase (\%) \\
\hline 1. & Pangan & 1.750 .397 & 53,4 \\
\hline 2. & Non Pangan & 1.528 .254 & 46,6 \\
\hline & Jumlah & 3.278 .651 & 100 \\
\hline
\end{tabular}

Sumber : Pengolahan Data Primer, 2020.

Berdasarkan hasil proporsi pengeluaran pangan terhadap pengeluaran total rumah tangga nelayan di Desa Lero bahwa rumah tangga nelayan memiliki tingkat kesejahteraan yang rendah dengan skor 1.

b. Tingkat Kesejahteraan Berdasarkan Pendidikan Nelayan

Indikator kesejahteraan yang dapat digunakan untuk mengetahui kualitas sumber daya manusia yaitu tingkat pendidikan yang telah ditamatkan (BPS, 2011). Semakin tinggi pendidikan, maka semakin besar kualitas sumberdaya manusianya dan semakin tinggi peluang untuk mendapatkan pekerjaan sehingga semakin terbuka harapan untuk hidup seiahtera.

Tabel 5. Tingkat Pendidikan Nelayan di Desa Lero

Tingkat Pendidikan Jumlah Responden Presentase (\%)

\begin{tabular}{lcc}
\hline Tamat SD & 17 & 53,1 \\
\hline Tamat SMP & 7 & 21,9 \\
\hline Tamat SMA & 8 & 25 \\
\hline Jumlah & 32 & 100
\end{tabular}

Sumber : Pengolahan Data Primer, 2020. 
Untuk mengukur tingkat kesejahteraan nelayan berdasarkan pendidikan digunakan rumus Indeks Pendidikan (IP) sebagai berikut :

$$
\begin{aligned}
\text { IP } & =2 / 3 \text { Indeks }(\mathrm{MH})+1 / 3 \text { Indeks (MYS) } \\
& =(2 / 3 \times 100)+(1 / 3 \times 8,53) \\
& =69,51
\end{aligned}
$$

Indeks pendidikan tabel 5 menunjukkan bahwa nelayan di desa Lero lebih banyak yang melek huruf dan cukup lama dalam mengikuti pendidikan, sehingga kualitas nelayan dalam penguasaan ilmu pengetahuan maupun keterampilan baik, meskipun mereka hanya tamatan SD. Hasil pada indeks pendidikan menunjukkan bahwa nelayan di desa Lero mendapat skor 3 yaitu $>60 \%$. Tingkat pendidikan yang rendah merupakan salah satu penyebab rendahnya kemampuan masyarakat pesisir dalam menangkap ikan (Rukin et al., 2018).

c. Tingkat Kesejahteraan Berdasarkan Kesehatan

Indikator kesehatan dapat dilihat dari keluhan kesehatan yang dialami, untuk menghitung kesejahteraan nelayan di Desa Lero berdasarkan aspek kesehatan dapat dilakukan dengan cara mencatat keadaan kesehatan anggota keluarga dalam sebulan yaitu adanya keluhan kesehatan atau tidak, selain itu keterjangkauan biaya berobat dan harga obat-obatan, penanganan/pelayanan berobat yang baik dan

\begin{tabular}{|c|c|c|c|c|c|}
\hline No. & Indikator & Kategori & $\begin{array}{c}\text { Jumlah } \\
\text { Responden }\end{array}$ & $\begin{array}{c}\text { Presentase } \\
(\%)\end{array}$ & Skor \\
\hline \multirow[t]{3}{*}{1.} & \multirow{3}{*}{$\begin{array}{l}\text { Kesehatan Anggota } \\
\text { Keluarga }\end{array}$} & Bagus & 29 & 91 & \multirow{3}{*}{3} \\
\hline & & Sedang & 3 & 9 & \\
\hline & & Kurang & - & - & \\
\hline \multirow[t]{3}{*}{2.} & \multirow[t]{3}{*}{ Biaya Berobat } & Terjangkau & 26 & 81 & \multirow{3}{*}{3} \\
\hline & & $\begin{array}{c}\text { Cukup } \\
\text { Terjangkau }\end{array}$ & 6 & 19 & \\
\hline & & $\begin{array}{c}\text { Sulit } \\
\text { Terjangkau }\end{array}$ & - & - & \\
\hline \multirow[t]{3}{*}{3.} & Penanganan & Baik & 21 & 66 & \multirow{3}{*}{3} \\
\hline & Berobat & Sedang & 10 & 31 & \\
\hline & & Kurang & 1 & 3 & \\
\hline \multirow[t]{3}{*}{4.} & \multirow[t]{3}{*}{ Harga Obat-obatan } & Terjangkau & 21 & 66 & \multirow{3}{*}{3} \\
\hline & & $\begin{array}{c}\text { Cukup } \\
\text { Teriangkau }\end{array}$ & 11 & 34 & \\
\hline & & $\begin{array}{c}\text { Sulit } \\
\text { Terjangkau }\end{array}$ & - & - & \\
\hline \multirow[t]{4}{*}{5.} & Alat Kontrasepsi & $\begin{array}{l}\text { Mudah } \\
\text { didapat }\end{array}$ & 23 & 72 & \multirow{3}{*}{3} \\
\hline & & $\begin{array}{l}\text { Cukup } \\
\text { Mudah }\end{array}$ & 9 & 28 & \\
\hline & & $\begin{array}{c}\text { Sulit } \\
\text { didapat }\end{array}$ & - & - & \\
\hline & & Jumlah & & & 15 \\
\hline
\end{tabular}
kemudahan mendapatkan alat kontrasepsi.

\section{Tabel 6. Rata-Rata Kesejahteraan Nelayan Berdasarkan Aspek Kesehatan}

Sumber : Pengolahan Data Primer, 2020. 
Hasil skoring tabel 6 menunjukkan bahwa kesejahteraan nelayan di Desa Lero berdasarkan 5 aspek kesehatan yang masing-masing indikator mendapatkan skor 3 sehingga tingkat kesejahteraan nelayan berdasarkan kesehatan dalam kriteria bagus dengan jumlah skor 15 .

d. Tingkat Kesejahteraan Berdasarkan Kualitas Tempat Tinggal

Tabel 7. Rata-rata Kesejahteraan Nelayan Berdasarkan Kualitas Tempat Tinggal

\begin{tabular}{|c|c|c|c|c|c|}
\hline No. & Indikator & Kategori & $\begin{array}{c}\text { Jumlah } \\
\text { Responden }\end{array}$ & $\begin{array}{c}\text { Presentase } \\
(\%)\end{array}$ & Skor \\
\hline \multirow[t]{5}{*}{1.} & Jenis Atap & Genteng & - & - & \multirow{5}{*}{3} \\
\hline & & Asbes & - & - & \\
\hline & & Seng & 29 & 91 & \\
\hline & & Bambu & - & - & \\
\hline & & Daun/Jerami & 3 & 9 & \\
\hline \multirow[t]{4}{*}{2.} & Jenis & Tembok & 22 & 69 & \multirow{4}{*}{4} \\
\hline & Dinding & Setengah Tembok & 1 & 3 & \\
\hline & & Kayu & 9 & 28 & \\
\hline & & Bambu & - & - & \\
\hline \multirow[t]{5}{*}{3.} & Jenis Lantai & Keramik & 1 & 3 & \multirow{5}{*}{3} \\
\hline & & Ubin & 3 & 9 & \\
\hline & & Plester & 27 & 84 & \\
\hline & & Kayu & 1 & 3 & \\
\hline & & Tanah & - & - & \\
\hline \multirow[t]{4}{*}{4.} & Luas Lantai & Luas $\left(>100 \mathrm{~m}^{2}\right)$ & 1 & 3 & \multirow{3}{*}{1} \\
\hline & & Sedang $\left(50 \mathrm{~m}^{2}-100 \mathrm{~m}^{2}\right)$ & 11 & 34 & \\
\hline & & Sempit $\left(<50 \mathrm{~m}^{2}\right)$ & 20 & 63 & \\
\hline & & Jumlah & & & 11 \\
\hline
\end{tabular}

Sumber : Pengolahan Data Primer, 2020.

Semakin baik kondisi rumah yang ditempati oleh suatu rumah tangga bisa dikatakan semakin sejahtera pula rumah tangga tersebut (Siregar et al., 2017).

Hasil skoring tabel 7 menunjukkan bahwa tingkat kesejahteraan nelayan di Desa Lero berdasarkan aspek kualitas tempat tinggal mendapatkan jumlah skor 11. Berdasarkan jumlah skor tersebut rata-rata nelayan di Desa Lero masuk kriteria Semi Permanen pada gambar 1 kondisi rumah semi permanen

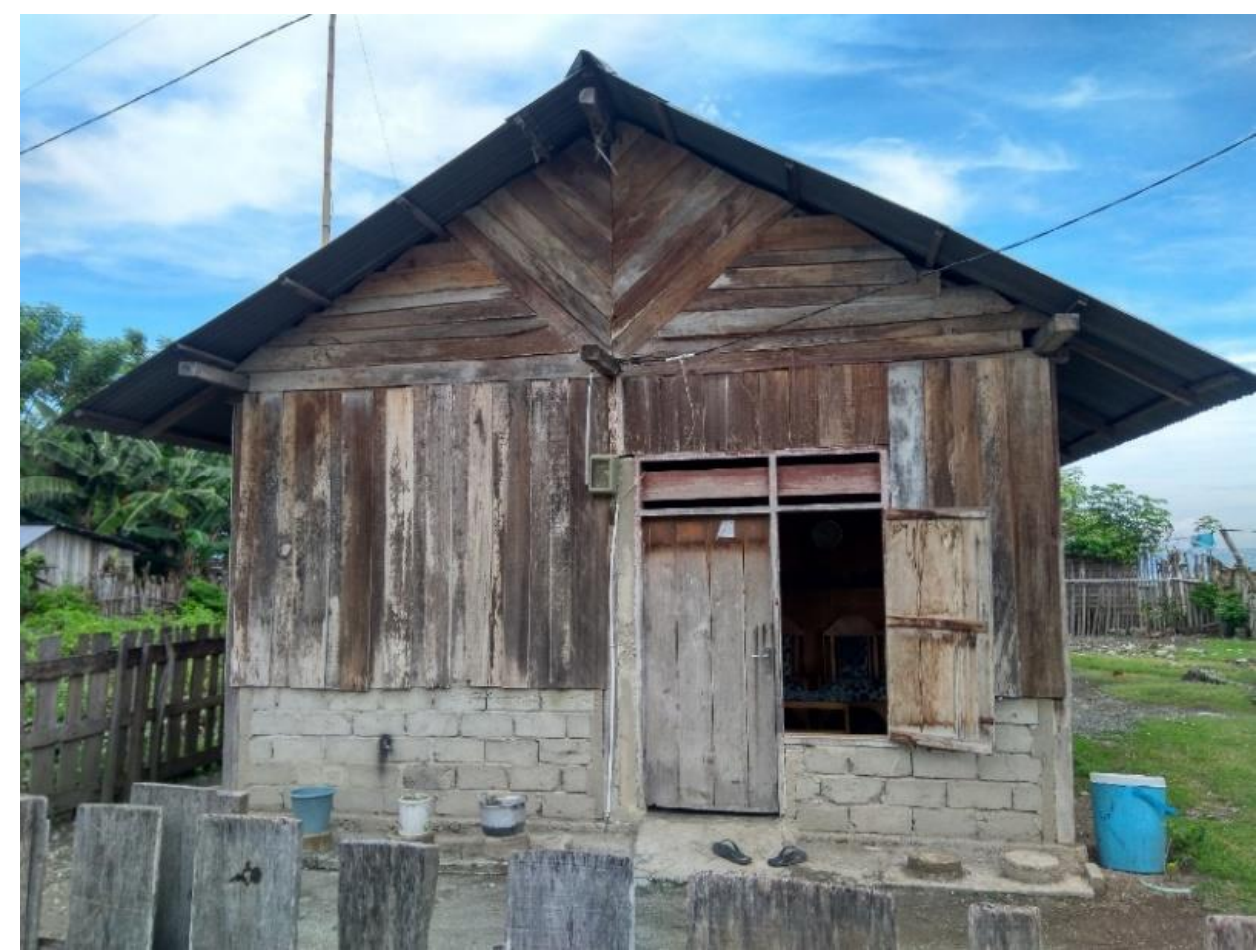


e. Tingkat Kesejahteraan Berdasarkan Fasilitas Tempat Tinggal

Salah satu ukuran dari kenyamanan tempat tinggal adalah fasilitas tempat tinggal yang mencukupi.

Tabel 8. Rata-rata Kesejahteraan Nelayan Berdasarkan Fasilitas Tempat Tinggal

\begin{tabular}{|c|c|c|c|c|c|}
\hline No. & Indikator & Kategori & $\begin{array}{c}\text { Jumlah } \\
\text { Responden }\end{array}$ & $\begin{array}{c}\text { Presentase } \\
(\%)\end{array}$ & Skor \\
\hline \multirow[t]{3}{*}{1.} & \multirow{3}{*}{ Sumber Penerangan } & Listrik & 32 & 100 & \multirow{3}{*}{3} \\
\hline & & Petromax & - & - & \\
\hline & & Pelita & - & - & \\
\hline \multirow[t]{4}{*}{2.} & \multirow[t]{4}{*}{ Sumber Air } & PDAM & 16 & 50 & \multirow{4}{*}{4} \\
\hline & & Sumur Bor & 7 & 22 & \\
\hline & & Mata Air & 9 & 28 & \\
\hline & & Air Hujan & - & - & \\
\hline \multirow[t]{3}{*}{3.} & \multirow[t]{3}{*}{ MCK } & Milik Sendiri & 24 & 75 & \multirow{3}{*}{3} \\
\hline & & Umum & 8 & 25 & \\
\hline & & Sungai/Laut & - & - & \\
\hline \multirow[t]{3}{*}{4.} & \multirow[t]{3}{*}{ Bahan Bakar } & Gas & 29 & 91 & \multirow{3}{*}{3} \\
\hline & & Minyak Tanah & - & & \\
\hline & & $\begin{array}{l}\text { Arang/Kayu } \\
\text { Bakar }\end{array}$ & 3 & 9 & \\
\hline \multirow[t]{3}{*}{5.} & \multirow[t]{3}{*}{ Pendingin Ruangan } & $\begin{array}{c}\text { Air Condisioner } \\
(\mathrm{AC})\end{array}$ & - & - & \multirow{3}{*}{1} \\
\hline & & Kipas Angin & 14 & 44 & \\
\hline & & Alam & 18 & 56 & \\
\hline \multirow[t]{3}{*}{6.} & \multirow[t]{3}{*}{ Jenis Kendaraan } & Mobil Pribadi & - & - & \multirow{3}{*}{2} \\
\hline & & Sepeda Motor & 25 & 78 & \\
\hline & & Kendaraan Umum & 7 & 22 & \\
\hline \multirow[t]{4}{*}{7.} & \multirow[t]{4}{*}{ Luas Pekarangan } & Luas $\left(>15 \mathrm{~m}^{2}\right)$ & 21 & 66 & \multirow{3}{*}{3} \\
\hline & & $\begin{array}{c}\text { Sedang }\left(8 m^{2}-15\right. \\
\left.m^{2}\right)\end{array}$ & 4 & 12 & \\
\hline & & Sempit $\left(<8 m^{2}\right)$ & 7 & 22 & \\
\hline & & Jumlah & & & 19 \\
\hline
\end{tabular}

Sumber : Pengolahan Data Primer, 2020.

Berdasarkan tabel 14 rata-rata kesejahteraan nelayan berdasarkan fasilitas tempat tinggal menunjukkan bahwa jumlah skor adalah 19 yang berarti fasilitas tempat tinggal nelayan masuk kategori lengkap namun cukup sederhana dan mencirikan rumah lokal tradisional oleh masyarakat asli di Kabupaten Donggala. Ciri-ciri lingkungan permukiman nelayan merupakan perpaduan pola pikir manusia dan budaya yang menghasilkan ciri lingkungan yang mudah dikenali melalui struktur fisik rumah, serta aktivitas masyarakat di lingkungan tersebut (Bahar, 2019).

f. Tingkat Kesejahteraan Berdasarkan Status Kepemilikan Rumah Tinggal

Tabel 9. Rata-rata Kesejahteraan Nelayan Berdasarkan Status Kepemilikan Rumah Tinggal

\begin{tabular}{|c|c|c|c|c|c|}
\hline No. & Indikator & Kategori & $\begin{array}{c}\text { Jumlah } \\
\text { Responden }\end{array}$ & $\begin{array}{c}\text { Presentase } \\
(\%)\end{array}$ & Skor \\
\hline \multirow[t]{4}{*}{1.} & \multirow[t]{4}{*}{ Status Kepemilikan } & Milik Sendiri & 25 & 78 & \multirow{3}{*}{3} \\
\hline & & Sewa/Kontrak & - & - & \\
\hline & & Milik Orang tua/Saudara & 7 & 22 & \\
\hline & & Jumlah & 32 & 100 & \\
\hline
\end{tabular}

Sumber : Pengolahan Data Primer, 2020. 
Berdasarkan tabel 9 rata-rata kesejahteraan nelayan berdasarkan status kepemilikan rumah tinggal menunjukkan bahwa rata-rata nelayan sudah memiliki rumah sendiri sebesar $78 \%$ sehingga mendapat skor 3.

g. Tingkat Kesejahteraan Berdasarkan Kemudahan Akses TIK

Semakin banyak penduduk yang memiliki akses TIK dan terus mengikuti kemajuan teknologi maka dapat dipastikan kesejahteraan akan semakin meningkat (BPS, 2011).

\begin{tabular}{|c|c|c|c|c|c|}
\hline No. & Indikator & Kategori & $\begin{array}{c}\text { Jumlah } \\
\text { Responden }\end{array}$ & $\begin{array}{c}\text { Presentase } \\
(\%)\end{array}$ & Skor \\
\hline \multirow[t]{4}{*}{1.} & \multirow{4}{*}{$\begin{array}{l}\text { Kepemilikan } \\
\text { Alat TIK }\end{array}$} & Memiliki HP dan Komputer & - & & \multirow{4}{*}{2} \\
\hline & & $\begin{array}{c}\text { Memiliki Komputer dan } \\
\text { Tidak Memiliki HP } \\
\end{array}$ & - & & \\
\hline & & $\begin{array}{l}\text { Memiliki HP dan Tidak } \\
\text { Memiliki Komputer }\end{array}$ & 23 & 72 & \\
\hline & & Tidak Memiliki Keduanya & 9 & 28 & \\
\hline \multirow[t]{4}{*}{2.} & \multirow{4}{*}{$\begin{array}{l}\text { Jenis Jaringan } \\
\text { Handphone }\end{array}$} & $4 \mathrm{G}$ & 8 & 25 & \multirow{4}{*}{2} \\
\hline & & $3 \mathrm{G}$ & 1 & 3 & \\
\hline & & $2 \mathrm{G}$ & 14 & 44 & \\
\hline & & Tidak ada & 9 & 28 & \\
\hline \multirow[t]{3}{*}{3.} & \multirow{3}{*}{$\begin{array}{l}\text { Keperluan } \\
\text { Akses Internet }\end{array}$} & Bisnis Online & 1 & 3 & \multirow{3}{*}{1} \\
\hline & & $\begin{array}{c}\text { Mengakses } \\
\text { Informasi/Hiburan }\end{array}$ & 8 & 25 & \\
\hline & & Tidak ada & 23 & 72 & \\
\hline \multirow[t]{4}{*}{4.} & Keperluan & Berdagang & 10 & 31 & \multirow{3}{*}{2} \\
\hline & Menggunakan & Komunikasi & 13 & 41 & \\
\hline & Handphone & Tidak Ada & 9 & 28 & \\
\hline & & Jumlah & & & 7 \\
\hline
\end{tabular}

Sumber : Pengolahan Data Primer, 2020.

Hasil skoring menunjukkan bahwa tingkat kesejahteraan nelayan di Desa Lero berdasarkan aspek kemudahan mengakses TIK adalah masuk kategori kurang dengan jumlah skor 7 .

h. Komposit Data Tingkat Kesejahteraan Berdasarkan Kriteria BPS

Setelah data dari 7 indikator berdasarkan kriteria BPS digabungkan dapat diketahui tingkat kesejahteraan nelayan di Desa Lero dapat diketahui melalui tabel berikut ini :

Tabel 11. Komposit Data Kesejahteraan Berdasarkan Kriteria BPS

\begin{tabular}{llc}
\hline No. & \multicolumn{1}{c}{ Indikator } & Skor \\
\hline 1. & Pengeluaran/Konsumsi Rumah Tangga & 1 \\
\hline 2. & Pendidikan & 3 \\
\hline 3. & Kesehatan & 3 \\
\hline 4. & Kualitas Tempat Tinggal & 2 \\
\hline 5. & Fasilitas Tempat Tinggal & 3 \\
\hline 6 & Status Kepemilihan Rumah Tinggal & 3 \\
\hline 7. & Kemudahan Mengakses TIK & 1 \\
\hline & Jumlah & 15 \\
\hline
\end{tabular}

Berdasarkan penjumlahan tabel 11 Komposit data kesejahteraan berdasarkan kriteria BPS menunjukkan bahwa jumlah skor adalah 15, sehingga berdasarkan tingkat kesejahteraan, dapat diketahui rata-rata nelayan di Desa Lero berada pada tingkat kesejahteraan sedang. Kondisi kesejahteraan nelayan di Desa Lero serupa 
dengan kesejahteraan masyarakat nelayan di pesisir Jawa Barat. Muflikhati et al. (2010) menyatakan bahwa meskipun keluarga nelayan memiliki pendapatan yang relatif besar, akan tetapi penggunaan pendapatannya masih diprioritaskan pada kebutuhan dasar (pangan) dan bahkan untuk hal-hal yang kurang bermanfaat seperti rokok, jajan, atau minuman keras. Guna meningkatkan kesejahteraan nelayan diperlukan keanekaragaman mata pencaharian rumahtangga nelayan termasuk peningkatan nilai tambah komoditi perikanan (Widjajanti et al., 2019). Untuk diperlukan pendidikan dan pelatihan bagi anggota rumahtangga nelayan guna meningkatkan keterampilan pengelolaan usaha guna meningkatkan pendapatan (Cahaya, 2015).

\subsection{Keterkaitan Penelitian dengan Pendidikan Geografi}

Salah satu cabang ilmu geografi adalah Geografi Manusia yang merupakan cabang geografi yang bidang kajiannya adalah aspek keruangan gejala dipermukaan bumi dengan manusia sebagai objek studinya yaitu mencakup aspek kependudukan, aspek aktivitas yang meliputi aspek ekonomi, aktivitas politik, aktivitas sosial dan budayanya. Penelitian ini merupakan penelitian dalam konteks geografi yang mencakup aktivitas ekonomi masyarakat nelayan di Desa Lero dalam mengelola sumberdaya alamnya. Salah satu sumberdaya alam yang dimiliki Desa Lero adalah sumberdaya perikanan, sehingga dengan adanya potensi perikanan tersebut dimanfaatkan masyarakat Desa Lero untuk memenuhi kebutuhan hidup dengan bekerja sebagai nelayan.

\section{Kesimpulan}

Berdasarkan hasil dan pembahasan yang telah diuraikan pada bab sebelumnya maka diperoleh kesimpulan bahwa Tingkat kesejahteraan nelayan di Desa Lero, Kecamatan Sindue, Kabupaten Donggala menurut Bank Dunia berada pada kategori penduduk miskin absolut. Hal ini dikarenakan pendapatan bersih yang diperoleh nelayan di Desa Lero selama sebulan hanya sebesar Rp. 839.413. Jumlah tersebut kurang dari ketentuan Bank Dunia yaitu US\$ 60/kapita/bulan atau jika dirupiahkan sebesar Rp. 900.000/bulan. Sedangkan, Tingkat kesejahteraan nelayan di Desa Lero, Kecamatan Sindue, Kabupaten Donggala berdasarkan kriteria BPS berada pada tingkat sedang dengan jumlah skor sejumlah 15. Jumlah skor tersebut dihasilkan dari penjumlahan 7 indikator yaitu pengeluaran/konsumsi rumah tangga dengan skor 1, pendidikan dengan skor 3, kesehatan dengan skor 3, kualitas tempat tinggal dengan skor 2, fasilitas tempat tinggal dengan skor 3, status kepemilikan rumah tinggal dengan skor 3 dan kemudahan mengakses Teknologi Informasi dan Komunikasi (TIK) dengan skor 1.

\section{Referensi}

Anonim. (2020). Monografi Desa Lero. Kantor Desa Lero.

Arikunto, S. (2013). Prosedur Penelitian Suatu Pendekatan Praktik. Rineka Cipta.

Bahar, F. (2019). Environmental Characteristics of Fishermen's Settlements as a Form of Local Wisdom of Coastal Communities in Karangsari Village, Tuban. Local Wisdom: Jurnal Ilmiah Kajian Kearifan Lokal, 11(1), 53-66. https://doi.org/10.26905/lw.v11i1.2712

BPS. (2011). Indikator Kesejahteraan Rakyat. Badan Pusat Statistik.

BPS. (2019). Indikator Kesejahteraan Rakyat Provinsi Sulawesi Tengah Tahun 2019. Badan Pusat Statistik Provinsi Sulawesi Tengah.

Cahaya, A. (2015). Fishermen Community in the Coastal Area: A Note from Indonesian Poor Family. Procedia Economics and Finance, 26(15), 29-33. https://doi.org/10.1016/s2212-5671(15)00801-1

Erlania, E., \& Radiarta, I. N. (2014). Management of sustainable seaweed (Kappaphycus alvarezii) aquaculture in the context of climate change mitigation. Indonesian Aquaculture Journal, 9(1), 65. https://doi.org/10.15578/iaj.9.1.2014.65-72

Firdaus, M., \& Witomo, M. (2014). PENDAPATAN RUMAH TANGGA NELAYAN PELAGIS BESAR DI SENDANG BIRU , KABUPATEN MALANG, JAWA TIMUR Analysis Of Welfare and Household Income Inequality of Large Pelagic. 155-168.

Fitri, D. (2020). Dua WIlayah di Donggala dilanda Banjir Bandang. KABAR24. 
Kobi, W., \& Hendra, H. (2020). KAJIAN GEOGRAFI EKONOMI: STUDI KASUS KONDISI SOSIAL EKONOMI MASYARAKAT SUKU BAJO DI POPAYATO, GORONTALO. JAMBURA GEO EDUCATION JOURNAL, 1(1), 16-25. https://doi.org/10.34312/jgej.v1i1.4637

Manggabarani, I. (2016). Kajian Sosial Ekonomi Masyarakat Nelayan yang Bermukim di Pesisir Pantai (Studi Kasus Lingkungan Luwaor Kecamatan Pamboang, Kabupaten Majene). Agrovital, 1(1), 27-33.

Muflikhati, I., Sumarwan, U., Fahrudin, A., \& Puspitawati, H. (2010). Kondisi Sosial Ekonom dan tingkat kesejahteraan keluarga: kasus di wilayah pesisir Jawa Barat. Jur. Ilm. Kel. \& Kons, 3(1), 1-10.

Nurwati, N. (2008). Kemiskinan: Model Pengukuran, Permasalahan dan Alternatif Kebijakan. Jurnal Kependudukan Padjadjaran, 10(1), 245387.

Rukin, Rahman, B., Toha, A., \& Gianawati, N. D. (2018). Coastal Rural Community Economic Development As a Poverty Reduction Efforts. The International Journal of Social Sciences and Humanities Invention, 5(4), 4627-4633. https://doi.org/10.18535/ijsshi/v5i4.12

Sabari, Y. H. (2010). Metodologi Penelitian Wilayah Kontemporer. Pustaka Pelajar.

Siregar, N. R., Suryana, A. A. H., Rostika, R., \& Nurhayati, A. (2017). Analisis Tingkat Kesejahteraan Nelayan Buruh Alat Tangkap Gill Net di Desa Sungai Buntu Kecamatan Pedes Kabupaten Karawang. Jurnal Perikanan Dan Kelautan, VIII(2), 112-117.

Sudarmo, A. P., Baskoro, M. S., Wiryawan, B., Wiyono, E. S., \& Monintja, D. R. (2015). Social Economics Characteristics Of Coastal Small-Scale Fisheries In Tegal City Indonesia. International Journal of Scientific \& Technology Research, 4(1), 85-88.

Sugiharto, E. (2007). Tingkat Kesejahteraan Masyarakat Nelayan Desa Benua Baru Ilir Berdasarkan Indikator Badan Pusat Statistik. Epp, 4(2), 32-36.

Sugiyono. (2008). Metode Penelitian Kuantitatif, Kualitatif dan R and D. Alfabeta.

Sugiyono. (2015). Metode Penelitian Kuantitatif, Kualitatif, dan R\&D. Alfabeta.

Sugiyono. (2018). Metode Penelitian Kuantitatif, Kualitatif, dan R\&D. Alfabeta.

Widjajanti, W. W., Antariksa, A., Leksono, A. ., \& Subadyo, A. T. (2019). Cultural Study of Fisherman Community in The Settlement, Brondong, Lamongan, East Java. International Seminar of Research Month Science and Technology for People Empowerment, 2018(2018), 276-285. https://doi.org/10.11594/nstp.2019.0238 